\title{
Calcium absorption in the normal, bile-duct ligated, and cirrhotic rat, with observations on the effect of long- and medium-chain triglycerides
}

\author{
A. K. KEHAYOGLOU, H. S. WILliAMS, W. F. WHIMSTER, \\ AND C. D. HOLDSWORTH ${ }^{1}$ \\ From the Departments of Medicine, Pathology, and Medical Physics, Royal Free Hospital, London
}

There are numerous reports of bone thinning in association with disease of the liver and biliary system. In cirrhosis of the liver, both osteomalacia and osteoporosis have been reported. Osteomalacia has been attributed to either malabsorption or lack of storage of vitamin $\mathrm{D}$, and osteoporosis variously to hypoalbuminaemia, endocrine disorders, or malabsorption of calcium (Cocchi, 1951; Lichtwitz, Cachin, Hioco, Tutin, and Sèze, 1959; Bour, Battesti, and Schaison, 1963). There have, however, been no systematic studies of calcium absorption and metabolism in the presence of cirrhosis of the liver in either man or in animals.

In animals with obstructive jaundice, on the other hand, calcium malabsorption and bone disease has been well documented. The importance of bile salts in calcium metabolism was first demonstrated by Pavlov (1905), who noted that osteoporosis developed in biliary fistula dogs. Wisner and Whipple (1922) confirmed this observation, and Buchbinder and Kern (1927) showed a progressive fall in the serum calcium of puppies after ligation of the common bile duct. In man with prolonged obstructive jaundice and biliary cirrhosis, the development of bone thinning (Seidel, 1910; Snapper, Seely, Falk, and Feder, 1954; Atkinson, Nordin, and Sherlock, 1956) and calcium malabsorption (Kehayoglou, Holdsworth, Agnew, Whelton, and Sherlock, 1968) has also been well documented.

The action of bile acids in increasing calcium absorption could either be indirect through vitamin D or direct. Vitamin $\mathbf{D}$ is necessary for efficient calcium absorption, and vitamin $D$ is not absorbed from the gut in the absence of bile (Greaves and Schmidt, 1932; Schachter, Finkelstein, and Kowarski, 1964).

The experiments described in the present paper were designed to study in rats the effect of biliary obstruction for varying periods of time on the

${ }^{1}$ Address correspondence to Dr C. D. Holdsworth, G-I Laboratory, St. Leonard's Hospital, Nuttall Street, London N.1. absorption of oral calcium chloride. To elucidate the extent to which fat may influence calcium absorption under these conditions calcium absorption was studied in the presence of long-chain triglycerides and medium-chain triglycerides in both normal and acutely bile duct-ligated animals. Finally the effect of experimental cirrhosis on bone development and calcium absorption has been assessed.

\section{MATERIAL AND METHODS}

MATERIALS Radioactive calcium- 45 or calcium- 47 was obtained as the chloride from the Radiochemical Centre, Amersham, Bucks, and doses were prepared by suitable dilution with normal saline and the addition of nonradioactive calcium chloride. Olive oil and mediumchain triglyceride were obtained from commercial sources. Gas liquid chromatography of the medium-chain triglyceride showed the constituent fatty acids to be largely octanoic acid $\left(\mathrm{C}_{8}\right)(77 \%)$ and decanoic acids $\left(\mathbf{C}_{10}\right)$ $(23 \%)$, with less than $0.5 \%$ of lauric acid $\left(\mathrm{C}_{10}\right)$ and only traces of $\mathrm{C}_{6}, 7$ and, fatty acids.

ANIMAL PREPARATION Sprague-Dawley rats were used in all experiments. Their mean weight was $125 \mathrm{~g}$ (range from $80 \mathrm{~g}$ to $170 \mathrm{~g}$ ), and mean age 5 weeks. Female rats were used in all experiments apart from those concerned with the effect of carbon tetrachloride-induced cirrhosis on calcium absorption, for which male rats were used.

Bile duct ligation Under ether anaesthesia and aseptic conditions, laparotomy was performed and the common bile duct was cut at its mid-point between ligatures. The abdominal wall was then closed by sutures. Control rats underwent similar manipulations except that the bile duct remained intact. After recovery from anaesthesia the animals were allowed to resume their normal diets, and were fed until 12 hours before absorption experiments. The effectiveness of the bile duct occlusion was checked after killing the animals. The chronically bile duct-obstructed rats remained in good health, and their mean increase in body weight $(65 \mathrm{~g})$ was similar to the increase in weight of the control group $(70 \mathrm{~g})$. Histological examination of the liver of obstructed rats showed a varying degree of liver damage, but secondary biliary cirrhosis had not developed. 
Induction of cirrhosis with carbon tetrachloride Male Sprague-Dawley rats, weighing approximately $100 \mathrm{~g}$, fed on a normal laboratory diet, were exposed to carbon tetrachloride vapour twice weekly for 30 weeks in a $3 \times 2 \times 2 \mathrm{ft}$ chamber for 20 minutes after they became unconscious (Daniel, Prichard, and Reynell, 1952; Cameron and Karunaratne, 1936). An equal number of male rats of the same body weight were used as controls. Both groups of rats grew well. Final mean weight of 17 cirrhotic rats was $432 \pm 11 \mathrm{~g}$, and of 17 control rats $350 \pm 15.5 \mathrm{~g}(\mathrm{M} \pm 2$ S.E. $)$. Histological examination of the liver confirmed the presence of cirrhosis in all animals exposed to carbon tetrachloride.

ABSORPTION STUDIES Calcium absorption was studied after the following procedures, and in appropriate control experiments. (1) The effect of acute bile duct obstruction (two to four days) was studied on (a) absorption of isotopic calcium from aqueous solutions containing two different amounts of carrier calcium, $(b)$ absorption of isotopic calcium when mixed with long-chain triglyceride, and (c) absorption of calcium when mixed with medium-chain triglyceride. (2) Chronic bile duct obstruction (16 to 39 days) and (3) the induction of cirrhosis by carbon tetrachloride.

ADMINISTRATION OF DOSE In all experiments the oral dose was introduced perorally through a blunt-ended steel cannula directly into the stomach of the fasting nonanaesthetized rat. The dose contained a trace quantity of radioactive calcium (either ${ }^{45} \mathrm{CaCl}_{2}$, or ${ }^{47} \mathrm{CaCl}_{2}$ or both) with $1 \mathrm{mg}$ of non-radioactive calcium as calcium chloride. For the study of calcium absorption in the absence of fat, the dose was dissolved in $1 \mathrm{ml}$ of $0.9 \% \mathrm{w} / \mathrm{v}$ saline. For the study of calcium absorption in the presence of fat, the dose was dissolved in $0.5 \mathrm{ml}$ of $0.9 \%$ saline and administered with $0.5 \mathrm{ml}$ of either olive oil or mediumchain triglyceride. No attempt was made to prepare an emulsion.

MEASUREMENT OF ABSORPTION Two methods were used to assess calcium absorption: (1) measurement of the percentage of the absorbed dose of ${ }^{45} \mathrm{Ca}$ which was deposited in the femora after 24 hours, and (2) measurement of the whole body retention of ${ }^{47} \mathrm{Ca} 24$ hours after the dose. For bone deposition studies ${ }^{45} \mathrm{Ca}$ was chosen because it has a long half life (165 days) and is continuously available. It is, however, a beta-emitter and can only be counted after extraction from the bones, which can be tedious. For retention studies ${ }^{47} \mathrm{Ca}$ was used. This is a short-lived isotope (half life 4.7 days) but emits high energy gamma rays so that activity in the whole animal can be measured externally by a suitable gamma counter.

Femoral uptake of ${ }^{45} \mathrm{Ca} \quad{ }^{45} \mathrm{CaCl}_{2}$ was administered as described above. Twenty-four hours later the animal was killed by a blow on the head, both femurs were dissected out, and after drying at room temperature for 24 hours were weighed and then dry ashed at $600^{\circ} \mathrm{C}$ for 24 hours. After re-weighing, the ashed bones were crushed and dissolved in $5 \mathrm{ml}$ of $2 \mathrm{~N} \mathrm{HCl}$, and the volume was made up to $50 \mathrm{ml}$ with distilled water.
The procedure followed was that described by Humphreys (1965), the principle of which is to precipitate calcium as the oxalate, and to convert this to calcium perchlorate by a two-stage incineration with $60 \%$ perchloric acid. The calcium perchlorate was then solubilized in a scintillation fluid containing $20 \%$ tributyl phosphate in toluene with $0.3 \%$ of PPO, and the counts per minute (cpm) measured in a Nuclear Chicago scintillation counter. As a standard, $1 \mu \mathrm{Ci}^{45} \mathrm{CaCl}_{2}$ was dissolved in $50 \mathrm{ml}$ of distilled water with $40 \mathrm{mg}$ of nonradioactive calcium chloride, and subjected to the same procedure. An aliquot of the oral dose was counted in the same way.

Percentage ${ }^{45} \mathrm{Ca}$ femur uptake $(\mathrm{F})=$

$$
\frac{\mathrm{cpm} \text { of femoral extract }}{\mathrm{cpm} \text { of oral dose }} \times 100
$$

Whole body retention of ${ }^{47} \mathrm{Ca}$ Thirty minutes after administration of the dose the animal was placed in a tin and the radioactivity measured in a counter consisting of a ring of 6 Geiger tubes. Radiation from ${ }^{47} \mathrm{Sc}$, the main daughter product of ${ }^{47} \mathrm{Ca}$, was excluded by surrounding the container with a $2 \mathrm{~mm}$ sheet of lead. Twenty-four hours later the animal was killed and counted again in the ring counter after removal of the alimentary canal.

Whole body retention of ${ }^{47} \mathrm{Ca}(\mathrm{R})=$

$$
\frac{\mathrm{cpm} 24 \text { hours after dose }}{\mathrm{cpm} 30 \text { minutes after dose }} \times 100
$$

The correlation between the two methods was satisfactory, and is shown in Figure 1. Both methods could theoretically be invalid if a large and variable amount of the absorbed dose was excreted in the urine during the first 24 hours, but although this has not been measured in rats, in man the error introduced by neglecting urinary excretion is small and relatively constant (Agnew, Holdsworth, and Kehayoglou, 1967). Furthermore,

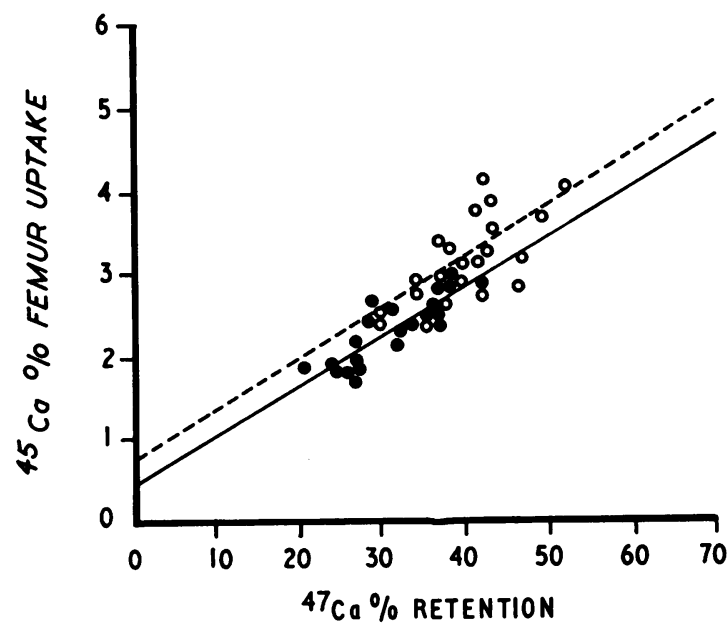

FIG. 1. Correlation between bone deposition of ${ }^{45} \mathrm{Ca}$ and whole body retention of ${ }^{45} \mathrm{Ca}$, after the oral administration of ${ }^{45} \mathrm{CaCl}_{2}$ mixed with olive oil. The regression lines are calculated.

$$
\begin{array}{ll}
\text { Bile duct-ligated rats }(r=0.84) \\
----\bigcirc & \text { Sham operated rats }(r=0.66)
\end{array}
$$


previous work has shown that deposition of ${ }^{45} \mathrm{Ca}$ in bone reflects the amount of calcium absorbed by the gut as measured by more direct methods (Sallis and Holdsworth, 1962), and it was concluded therefore that either of the two techniques described in this paper do in fact measure calcium absorption and that they could be used interchangeably. The possibility does exist that any depression of calcium absorption produced by vitamin $\mathrm{D}$ deficiency may be underestimated by either of these two methods, because of the smaller urinary calcium excretion of vitamin D-deficient animals. Sallis and Holdsworth (1962) found that bone deposition of isotope gave a satisfactory indication of calcium absorption in osteomalacic animals as well as in normal animals, so that any error introduced by neglecting urine excretion must be small.

The significance of the results were assessed by Student's test. All ranges shown are \pm two standard errors of the mean. The figures in parentheses in both tables and test refer to the number of rats in the experimental group.

\section{RESULTS}

ABSORPTION OF CALCIUM FROM AQUEOUS SOLUTION There was no significant difference between the absorption of calcium in acutely bile duct-obstructed rats, and in sham-operated animals (Table I).

When $50 \mathrm{mg}$ of calcium was used as a carrier dose in place of the normal $1 \mathrm{mg}$, absorption (R) in sham operated rats was slightly depressed, falling from $39.3 \pm 2.86$ (6) to $33.2 \pm 0.87$ (13) $(\mathrm{P}<0.02)$. In bile duct-obstructed animals the fall in calcium absorption (R) from $35.6 \pm 2.85(6)$ to $32.7 \pm 0.87$ (14), was not significant. As was found with the $1 \mathrm{mg}$ dose, bile duct ligation did not significantly depress the absorption of calcium chloride dissolved in isotonic sodium chloride.

ABSORPTION OF CALCIUM ADMINISTERED WITH LONGCHAIN TRIGLYCERIDES When the dose was mixed with long-chain triglyceride in the form of olive oil, bile duct ligation resulted in a considerable depression of calcium absorption, in contrast to the findings with an aqueous solution of calcium. The mean calcium absorption in the bile duct-ligated animals was only $67 \%$ of that in the control animals and this depression of calcium absorption was shown by both the techniques used (Fig. 1). On the other hand, olive oil did not depress the absorption of calcium in the sham operated rats.

ABSORPTION OF CALCIUM ADMINISTERED WITH MEDIUMCHAIN TRIGLYCERIDE In contrast to the findings with long-chain triglycerides, there was no significant depression of calcium absorption by medium chain triglyceride. Indeed, medium-chain triglycerides markedly stimulated calcium absorption in both sham operated and control animals. In a further series of experiments, using two groups of nine normal animals which had not been subjected to any surgical procedure, medium-chain triglycerides also significantly stimulated calcium absorption. Absorption (R) of calcium from an aqueous solution was $48 \% \pm 3.9$, and when mixed with medium chain triglyceride was $60 \% \pm 2.4(\mathrm{P}<0.02)$

CHRONIC BILE DUCT OBSTRUCTION In contrast to the effect of acute bile duct obstruction, chronic bile duct obstruction significantly depressed the absorption

TABLE I

EFFECT OF ACUTE BILE DUCT OBSTRUCTION ON ABSORPTION OF CALCIUM GIVEN IN AQUEOUS SOLUTION OR MIXED WITH LONG- OR MEDIUM-CHAIN TRIGLYCERIDES

\begin{tabular}{|c|c|c|c|c|c|c|}
\hline \multirow[t]{2}{*}{ Form of Administered Dose } & \multirow{2}{*}{$\begin{array}{l}\text { Mean Duration } \\
\text { of Obstruction } \\
\text { (days) }\end{array}$} & \multirow{2}{*}{$\begin{array}{l}\text { Carrier Dose } \\
\text { of } \mathrm{Ca}(\mathrm{mg})\end{array}$} & \multirow{2}{*}{$\begin{array}{l}\text { Method of } \\
\text { Absorption } \\
\text { Study }\end{array}$} & \multicolumn{3}{|l|}{ Absorption } \\
\hline & & & & Sham Operated & Obstructed & $\boldsymbol{P}$ \\
\hline Aqueous solution $\mathrm{CaCl}_{2}$ & $\begin{array}{l}3 \\
2\end{array}$ & $\begin{array}{l}1 \\
1\end{array}$ & $\begin{array}{l}\mathbf{F} \\
\mathbf{R}\end{array}$ & $\begin{array}{c}3.6 \pm 0.5 \quad(10) \\
39.3 \pm 2.86(6)\end{array}$ & $\begin{aligned} 3 \cdot 2 & \pm 0.26(11) \\
35 \cdot 6 & \pm 2.85(6)\end{aligned}$ & $\begin{array}{l}>0.5 \\
>0.5\end{array}$ \\
\hline $\mathrm{CaCl}_{2}+$ olive oil & $4 \cdot 5$ & 1 & $\mathbf{F}$ & $3.7 \pm 0.19(32)$ & $2.5 \pm 0.12(38)$ & $<0.001$ \\
\hline & $4 \cdot 5$ & 1 & $\mathbf{R}$ & $40 \cdot 0 \pm 2 \cdot 4$ & $31 \cdot 1 \pm 1 \cdot 86(22)$ & $<0.001$ \\
\hline $\mathrm{CaCl}_{2}+$ medium-chain triglyceride & $3 \cdot 5$ & 1 & $\mathbf{R}$ & $56.0 \pm 2.43(17)$ & $58 \cdot 0 \pm 2 \cdot 15(22)$ & $>0.3$ \\
\hline
\end{tabular}

TABLE II

EFFECT OF CHRONIC BILE DUCT OBSTRUCTION ON ABSORPTION OF CALCIUM FROM AN AQUEOUS SOLUTION OF CALCIUM CHLORIDE (1 $\mathrm{mg} \mathrm{Ca})$

\begin{tabular}{|c|c|c|c|c|c|c|c|c|}
\hline \multirow[t]{2}{*}{ Experiment } & \multirow{2}{*}{$\begin{array}{l}\text { Duration of } \\
\text { Obstruction } \\
\text { (days) }\end{array}$} & \multicolumn{3}{|l|}{ Absorption $(F)$} & \multicolumn{4}{|l|}{ Absorption $(R)$} \\
\hline & & Sham Operated & Obstructed & $\boldsymbol{P}$ & Sham Operated & Obstructed & $\boldsymbol{P}$ & \\
\hline $\begin{array}{l}1 \\
2 \\
3 \\
4\end{array}$ & $\begin{array}{l}16 \\
25 \\
33 \\
39\end{array}$ & $\begin{array}{l}3.3 \pm 0.58(6) \\
3.4 \pm 0.33(8) \\
4.8 \pm 0.98(7) \\
2.9 \pm 0.24(8)\end{array}$ & $\begin{array}{l}2.3 \pm 0.29(11) \\
2 \cdot 4 \pm 0.28(6) \\
3.3 \pm 1.3 \quad(6) \\
2 \cdot 3 \pm 0.28(5)\end{array}$ & $\begin{array}{l}<0.001 \\
<0.001 \\
<0.2 \\
<0.01\end{array}$ & $\begin{array}{l}40.88 \pm 6.1(6) \\
41 \cdot 55 \pm 4 \cdot 3(8) \\
\overline{37} \cdot 7 \pm 2 \cdot 1(8)\end{array}$ & $\begin{array}{l}30.48 \pm 4.4(11) \\
30.96 \pm 2.6(6) \\
\overline{33} .90 \pm 3.8(5)\end{array}$ & $\begin{array}{l}< \\
< \\
<\end{array}$ & $\begin{array}{l}0.02 \\
0.005 \\
0.1\end{array}$ \\
\hline Total & & $3.6 \pm 0.19(29)$ & $2 \cdot 57 \pm 0.17(28)$ & $<0.001$ & $39 \cdot 8 \pm 1 \cdot 2(22)$ & $31 \cdot 38 \pm 1.2(22)$ & $<$ & 0.001 \\
\hline
\end{tabular}


of calcium chloride in aqueous solution (Table II). The depression was apparent at 16 days, and did not become more pronounced over the following 23 days.

The percentage of loss of bone weight on ashing of the femoral bones was studied in both groups, as an indication of their mineral content. In chronically obstructed rats mean loss of weight on ashing was $50.5 \pm 0.5 \%(M \pm 2 S E)$, and in sham operated rats the corresponding figure was $49.5 \pm 0.7 \%$ $(\mathrm{M} \pm 2 \mathrm{SE})$, but the difference did not reach a definite degree of significance $(\mathrm{P}<0 \cdot 1)$.

CARBON TETRACHLORIDE-INDUCED CIRRHOSIS There was no significant difference (Table III) in the ${ }^{47} \mathrm{Ca}$ retention of the normal and cirrhotic rats $(P<0 \cdot 2)$.

There was no significant difference between the control and cirrhotic groups of rats in either weight gain, percentage of bone ash, femoral scores as assessed radiologically (Nordin, MacGregor, and Smith, 1965), and femoral bone length. Serum calcium and phosphorus were similar in the two groups at the end of the experiment, and the only significant differences were those resulting directly from the cirrhosis, ie, in spleen weight, liver weight, and serum alkaline phosphatase. Portal vein pressure was raised in six of the eight cirrhotic animals in which it was measured. Cirrhosis of the liver was evident on macroscopic examination of the liver and was confirmed histologically in all cases. The serum bilirubin was over $1.0 \mathrm{mg}$ per $100 \mathrm{ml}$ in only one rat, and this rat was also the only animal which developed ascites. Whole body retention of ${ }^{47} \mathrm{Ca}$ in this animal was $13.9 \%$, which is in the low normal range.

\section{DISCUSSION}

The study of calcium absorption in the intact animal was until recent years only possible by the use of balance techniques, in which dietary intake and faecal excretion of calcium was measured during a period of time extending over several days. Using radioactive isotopes of calcium it has become possible to devise acute experiments. Measurement of blood radioactivity within a few hours of the dose has been widely used (Webling and Holdsworth, $1965,1966)$, but it has been found in man that blood radioactivity after oral isotopic calcium can be affected by factors other than absorption (Agnew et al, 1967) and in this study a more direct method has therefore been chosen. The deposition of ${ }^{45} \mathrm{Ca}$ in bone has been used previously to measure calcium absorption and gives a valid indication of calcium absorption in both normal and vitamin D-deficient animals (Sallis and Holdsworth, 1962). Whole body retention of ${ }^{47} \mathrm{Ca}$ has been used in man as an index of calcium absorption (Deller, Worthley, and Martin 1965; Agnew et al, 1967). In rats it was found to be a rapid and convenient method with results which correlate well with those of bone deposition (Fig. 1).

Under the condition of our experiments acute biliary obstruction had no effect on the absorption of calcium chloride whether this was given in a small amount $(1 \mathrm{mg})$ or a large amount $(50 \mathrm{mg})$ of calcium, although in the sham operated rats percentage absorption of calcium was less when given with a larger carrier dose. Under similar conditions in rats, Lengemann and Dobbins (1958) found that the absorption of an oral dose of $30 \mathrm{mg}$ calcium chloride mixed with $1 \mathrm{mM}$ of glycine was unaffected by acute bile duct obstruction although stimulation of bile flow in normal animals did enhance calcium absorption. Webling and Holdsworth (1966) found in rats that absorption of the much more sparingly soluble salt calcium phosphate $\left(\mathrm{CaHPO}_{4}\right)$ was considerably diminished by ligation of the bile duct. They did not assess the result of this operation on absorption of the more soluble salt calcium chloride but they showed that certain bile salts could stimulate the absorption of this compound, although they have a much greater effect on the absorption of more sparingly soluble salts (Webling and Holdsworth, 1965). They presented evidence to support their view that this was due to the capacity of bile salts to form

TABLE III

EFFECT OF CARBON TETRACHLORIDE-INDUCED CIRRHOSIS ON CALCIUM METABOLISM

\begin{tabular}{|c|c|c|c|}
\hline & & $\begin{array}{l}\text { Seventeen } \\
\text { Cirrhotics }\end{array}$ & $\begin{array}{l}\text { Seventeen } \\
\text { Controls }\end{array}$ \\
\hline $\begin{array}{l}1 \\
2 \\
3 \\
4 \\
5 \\
6 \\
7 \\
8 \\
9\end{array}$ & $\begin{array}{l}{ }^{47} \text { Ca } \% \text { retention } \\
\% \text { loss of weight on ashing femur } \\
\text { Femoral score } \\
\text { Femoral length }(\mathrm{mm}) \\
\text { Serum calcium }(\mathrm{mg} / 100 \mathrm{ml}) \\
\text { Serum phosphorus }(\mathrm{mg} / 100 \mathrm{ml}) \\
\text { Serum alkaline phosphatase (IU) } \\
\text { Liver weight }(\mathrm{g}) \\
\text { Spleen weight }(\mathrm{g})\end{array}$ & $\begin{aligned} 20.7 & \pm 1.5 \\
47.77 & \pm 0.33 \\
42.0 & \pm 1.1 \\
39.8 & \pm 0.3 \\
9.9 & \pm 0.18 \\
5.6 & \pm 0.16 \\
54.0 & \pm 3.0 \\
17.8 & \pm 0.7 \\
2.4 & \pm 0.1\end{aligned}$ & $\begin{array}{l}23.0 \pm 1.6 \\
47.55 \pm 0.43 \\
44.0 \pm 0.85 \\
40.4 \pm 0.3 \\
9.4 \pm 0.27 \\
5.1 \pm 0.33 \\
24.0 \pm 2.5 \\
12.9 \pm 0.4 \\
1.5 \pm 0.1\end{array}$ \\
\hline
\end{tabular}


lipid soluble calcium complexes which are absorbed directly by the intestinal mucosa.

The possible effects of triglyceride on calcium absorption in both normal and biliary-obstructed rats are complex, even in short-term experiments where any effect secondary to changes in vitamin D absorption can be eliminated. In the normal animal, calcium salts can be solubilized in a mixture of fatty acids and bile acids, and Klinke (1928) and Verzár and McDougall (1936) suggested that such a mixture may form a soluble complex in the intestine that could be absorbed intact by the mucosal cell, ionic calcium being only liberated within the body. More modern physico-chemical studies have shown that a micellar solution of bile salts and monoglycerides can incorporate polyvalent cations such as calcium, and it has been suggested that this micellar solubilization could play a role in normal calcium absorption (Hofmann, 1965). Bile duct ligation could therefore diminish calcium absorption by interfering with micellar solubilization. In addition, bile salt deficiency leads to impaired fat absorption, and this could lead to impaired calcium absorption due to the formation of insoluble calcium soaps.

In the experiments described in this paper, calcium absorption in sham operated animals was found to be unaffected by olive oil, which consists largely of the long-chain triglyceride triolein. On the other hand, in normal, sham operated and bile duct-ligated rats, calcium absorption was markedly stimulated by a mixture of medium-chain triglycerides. The effect of medium-chain triglyceride was not studied after chronic bile duct ligation. Previous reports about the effect of dietary fat on calcium absorption have varied considerably according to the experimental conditions. Thus it may diminish absorption (Westerlund, 1934), increase absorption (Boyd, Crum, and Lyman, 1932; Knudson and Floody, 1940; Jones, 1942), or have no effect (Steggerda and Mitchell, 1951). In general it appears to be true that any deleterious effect of fat on calcium absorption increases in proportion to the molecular weight and melting point of the fat concerned (Westerlund, 1934; Calverley and Kennedy, 1949), so that tristearin and tripalmitin may depress calcium absorption but tributyrin or triolein do not (Westerlund, 1934), and French and Elliott (1943) found that in the albino rat olive oil only diminished dietary calcium absorption when given in large quantities. This may reflect the easier digestibility of the lower molecular weight triglycerides, or the greater solubility of the calcium salts of their constituent fatty acids (Bosworth, Bowditch, and Giblin, 1918). Telfer (1921) clearly identified the fact that both fatty acid chain length and intestinal $p \mathrm{H}$ affect calcium solubility within the lumen of the small intestine. Even if calcium is given as the chloride, the chloride ion is absorbed more rapidly than the calcium ion (Haldane, Hill, and Luck, 1923) and the calcium ions then associate with fatty acid, phosphate, or carbonate ions to form less soluble salts. The shorter chain fatty acids readily dissolve calcium carbonate and calcium phosphate, but in the presence of longer chain fatty acids insoluble calcium soaps are produced. The effect of medium-chain triglyceride on calcium absorption has not been previously studied, but the striking effect which we have demonstrated probably reflects intraluminal solubilization of calcium by mediumchain length fatty acids.

The finding that, in the absence of bile, olive oil depressed the absorption of calcium administered as calcium chloride is hardly surprising in view of what has already been stated about the importance of bile in dissolving fatty acids and calcium soaps. On the other hand, it would appear from our results that bile salts are not necessary for the absorption of calcium when given together with medium-chain triglyceride. Medium-chain triglycerides are relatively water soluble, are absorbed into the portal vein rather than lymphatics, do not need bile salts for digestion, and would be expected to form soluble calcium soaps which would themselves readily be absorbed.

In rats with prolonged bile duct obstruction, as in man (Kehayoglou et al, 1968), the absorption of calcium given as calcium chloride was considerably diminished. In man the absorptive defect is completely remedied by vitamin D (Kehayoglou et al, 1968), and it would appear probable that failure to absorb vitamin $\mathrm{D}$ in the absence of bile is also the cause of this defect in rats with prolonged biliary obstruction.

It is perhaps surprising after a period of bile duct obstruction sufficient to produce vitamin $D$ deficiency that there was no evidence of bone disease in our rats, radiologically. Bone ash content was slightly lower than in the control animals but this difference was not statistically significant. Overall growth of bile duct-obstructed animals was also satisfactory. It may be that bile salts are less essential for calcium absorption in rats than for some other animals, for in puppies biliary obstruction results in a fall in serum calcium and the development of osteomalacia (Buchbinder and Kern, 1927). Certainly rickets is a different condition in rats from the disease known by the same name in man and it does not occur on a diet deficient in vitamin $D$ unless the calcium and phosphorus content of the diet is unbalanced (Comar and Bronner, 1964). Alternatively, it may be that a longer period of obstruction than 
39 days may be necessary to produce evidence of bone disease.

Bone thinning is also said to be frequent in patients with cirrhosis even in the absence of biliary obstruction. In addition to the possible causes for this which have already been mentioned, it has been claimed that in animals with liver damage due to carbon tetrachloride the vitamin $\mathrm{D}$ requirement of rachitic rats is increased (Heymann, 1938). Calcium absorption has not previously been studied in animals with experimental cirrhosis, but our results in rats do not suggest that experimental cirrhosis has any effect on the absorption of soluble calcium, nor does it have any effect on bone growth, bone histology, or bone ash content. However, it is worthy of note that the one animal with jaundice and fluid retention did have rather low calcium absorption. The lower mean absorption of calcium in both cirrhotic and control rats is almost certainly due to the age of these animals being much greater than that of animals in all the previous experiments (Nicolaysen, Eeg-Larsen, and Malm, 1953).

\section{SUMMARY}

The absorption of calcium from solutions of calcium chloride was studied in unanaesthetized rats by either measuring bone deposition of ${ }^{45} \mathrm{Ca}$ or whole body retention of ${ }^{47} \mathrm{Ca}$.

In acutely bile duct-obstructed animals calcium absorption was significantly depressed when the oral dose was mixed with olive oil, but not when it was given as an aqueous solution, whereas in normal animals olive oil did not depress calcium absorption. In normal animals percentage calcium absorption was slightly but significantly depressed by increasing the carrier dose from $1 \mathrm{mg}$ to $50 \mathrm{mg}$ of calcium, but the size of carrier dose did not affect percentage absorption in the obstructed rats. Medium-chain triglyceride stimulated calcium absorption in both normal, sham operated, and bile duct-obstructed animals.

In chronically bile duct-obstructed animals calcium absorption from an aqueous solution of calcium chloride was significantly less than that found in control animals. The percentage of bone ash was not significantly reduced by chronic bile duct obstruction.

Carbon tetrachloride-induced cirrhosis did not affect calcium absorption, nor did it affect bone ash content.

The possible pathophysiological mechanisms are discussed.

Dr Joyce Bell performed the biochemical estimations in the cirrhotic rats, and Miss Pamela Middleton gave valuable technical assistance in the isotope studies. $\mathrm{Dr}$ F. H. Doyle gave helpful advice on the radiological assessment of bone thinning. We wish to thank Dr B. H. Billing and Professor Sheila Sherlock for their advice, suggestions, and encouragement.

C.D.H. is in receipt of a research grant from the North East Metropolitan Regional Hospital Board.

\section{REFERENCES}

Agnew, J. E., Holdsworth, C. D., and Kehayoglou, A. K. (1967). A comparison of three isotopic methods for the study of calcium absorption. In preparation.

Atkinson, M., Nordin, B. E. C., and Sherlock, S. (1956). Malabsorption and bone disease in prolonged obstructive jaundice. Quart. J. Med., 25, 299-312.

Bosworth, A. W., Bowditch, H. I., and Giblin, L. A. (1918). Studies of infant feeding. $X$. The digestion and absorption of fats. I. Calcium in its relation to the absorption of fatty acids. Amer. J. Dis. Child., 15, 397-407.

Bour, H., Battesti, J. P., and Schaison, G. (1963). Réflexions sur les troubles du métabolisme phospho-calcique dans les cirrhoses. A propos d'un cas avec ostéomalacie dominante et d'exploration de huit autres cirrhotiques. Presse méd., 71, 2772-2775.

Boyd, O. F., Crum, C. L., and Lyman, J. F. (1932). The absorption of calcium soaps and the relation of dietary fat to calcium utilization in the white rat. J. biol. Chem., 95, 29-41.

Buchbinder, W. C., and Kern, R. (1927). Blood calcium deficiency in experimental obstructive jaundice. Amer. J. Physiol., 80, 273 277.

Calverley, C. E., and Kennedy, C. (1949). The effect of fat on calcium and phosphorus metabolism in normal growing rats under a normal dietary regime. J. Nutr., 38, 165-175.

Cameron, G. R., and Karunaratne, W. A. E. (1936). Carbon tetrachloride cirrhosis in relation to liver regeneration. J. Path. Bact., 42, 1-21.

Cocchi, U. (1951). Hepatogene Osteoporosen. Radiol. clin. (Basel), 20, 362-382.

Comar, C. L., and Bronner, F. (1964). Mineral Metabolism, vol. 2, pt 1, p. 456. Academic Press, New York and London.

Daniel, P. M., Prichard, M. M. L., and Reynell, P. C. (1952). The portal circulation in experimental cirrhosis of the liver. $J$. Path. Bact., 64, 53-60.

Deller, D. J., Worthley, B. W., and Martin, H. (1965). Measurement of calcium-47 absorption by whole-body gamma spectrometry. Aust. Ann. Med., 14, 223-231.

French, C. E., and Elliott, R. F. (1943). The interrelation of calcium and fat utilization. J. Nutr., 25, 17-21.

Greaves, J. D., and Schmidt, C. L. A. (1932). Studies on calcium and phosphorus in bile-fistula dogs. Proc. Soc. exp. Biol. (N.Y.), 29, 373-377.

Haldane, J. B. S., Hill, R., and Luck, J. M. (1933). Calcium chloride acidosis. J. Physiol. (Lond.), 57, 301-306.

Heymann, W. (1938). Metabolism and mode of action of vitamin D. Amer. J. Dis. Child., 55, 913-923.

Hofmann, A. F. (1965). Clinical implications of physicochemical studies on bile salts. Gastroenterology, 48, 484-494.

Humphreys, E. R. (1965). An improved method for determining calcium-45 in biological materials. Int. J. appl. Radiat., 16, 345-348.

Jones, J. H. (1942). The relation of the $\mathrm{pH}$ of intestinal contents to calcium and phosphorus utilization. J. biol. Chem., 142, 557567.

Kehayoglou, A. K., Holdsworth, C. D., Agnew, J. E., Whelton, M. J., and Sherlock, S. (1968). Bone disease and calcium absorption in primary biliary cirrhosis, with special reference to vitamin D therapy. Lancet 1, 715-719.

Klinke, K. (1928). Neuere Ergebnisse der Calciumforschung. Ergebn. Physiol., 26, 235-319.

Knudson, A., and Floody, R. J. (1940). Fat as a factor in the healing of rickets with vitamin D. J. Nutr., 20, 317-325.

Lengemann, F. W., and Dobbins, J. W. (1958). The role of bile in calcium absorption. Ibid., 66, 45-54.

Lichtwitz, A., Cachin, M., Hioco, D., Tutin, M., and Sèze, S. de (1959). Le syndrome phosphocalcique des cirrhoses. Sem. Hôp. Paris, 35, 2399-2409.

Nicolaysen, R., Eeg-Larsen, N., and Malm, O. J. (1953). Physiology of calcium metabolism. Physiol. Rev., 33, 424-444. 
Nordin, B. E. C., MacGregor, J., and Smith, D. A. (1965). The incidence of osteoporosis in normal women: its relation to age and the menopause. Quart. J. Med., 35, 25-38.

Pavlov, I. P. (1905). Laboratornye nabliudeniia nad razmiagcheniem Kostei u sobaki. Trudy Obsch. russk. Vrach. S-Peterb., 72, 314-320. (Reprinted in German in Pavlov, I. P. (1952) Samtliche Werke, 6, 184-189).

Sallis, J. D., and Holdsworth, E. S. (1962). Influence of vitamin D on calcium absorption in the chick. Amer. J. Physiol., 203, 497505.

Schachter, D., Finkelstein, J. D., and Kowarski, S. (1964). Metabolism of vitamin D. I. Preparation of radioactive vitamin D and its intestinal absorption in the rat. J. clin. Invest., 43, 787796.

Seidel, H. (1910). Permanente Gallenfistel und Osteoporose beim Menschen. Munch. med. Wschr., 572, 2034-2036.

Snapper, I., Seely, R., Falk, S., and Feder, I. (1954). Osteomalacia in New York. Ann. intern. Med., 41, 893-909.
Steggerda, F. R., and Mitchell, H. H. (1951). The calcium balance of adult human subjects on high- and low-fat (butter) diets. J. Nutr., 45, 201-211.

Telfer, S. Y. (1931). The influence of free fatty acids in the intestinal contents on the excretion of calcium and phosphorus. Biochem. $J ., 15,347-354$.

Verzár, F., and McDougall, E. J. (1936). Absorption from the Intestine, p. 106. Longmans, Green, London.

Webling, D. D'A., and Holdsworth, E. S. (1965). The effect of bile, bile acids and detergents on calcium absorption in the chick. Biochem. J., 97, 408-421.

$\longrightarrow, \frac{-1}{660}$ (1966). Bile salts and calcium absorption. Ibid., 100, 652-

Westerlund, A. (1934). The effect of tributyrin on the faecal output of calcium in full grown rats. Lantbr Högsk. Annlr., 1, 1.

Wisner, F. P., and Whipple, G. H. (1922). Variations in output of bile salts and pigments during 24 hour periods. Amer. J. Physiol., $60,119-133$

\section{The August 1968 Issue \\ THE AUGUST 1968 ISSUE CONTAINS THE FOLLOWING PAPERS}

\section{Signposts}

Primary anorexia nervosa A. H. CRISP

Gastric intrinsic factor I. CHANARIN

Three cases of ischaemic colitis GEORGE H. DICKSON

Multiple tuberculous perforations of ileum w. G. PROUT

Crohn's disease and diffuse symmetrical periostitis G. NEALE, A. R. KELSALL, and F. H. DOYLE

Radiological findings in carcinoma of the colon complicating chronic ulcerative colitis JOHN J. FENNESSY, MARSHALL B. SPARBERG, and JOSEPH B. KIRSNER

The source of duodenal aspirate in man K. G. WORMSLEY

Action of pancreozymin preparations on gastric acid secretion M. NAKAMURA, S. NAKAJIMA, and D. F. MAGEE

Blood changes eight years after vagotomy with gastrojejunostomy compared with those after Polya partial gastrectomy ALAN G. COX, H. E. HUTCHISON, and C. A. J. WARDROP

Site and localization of duodenal ulcers: a study at operation R. M. KIRK

Gastric emptying rate of the water and fat phases of a mixed test meal in man C. A. CHANG, RICHARD $D$. MCKENNA, and IVAN T. BECK

Absorption and malabsorption of glycine and glycine peptides in man I. L. CRAFT, D. GEDDES, C. W. HYDE, IRENE J. WISE, and D. M. MATTHEWS
Retrospective review of 208 proved cases of anastomotic ulcer JOHN R. CONDON and NORMAN C. TANNER

Colonic motor activity and bowel function J. A. RITCHIE

Basal electrical activity in the anal canal in man W. J. WANKLING, B. H. BROWN, C. D. COLLINS, and H. L. DUTHIE Hypertrophic tuberculosis of the rectum P. R. HAWLEY, H. R. I. WOLFE, and J. M. FULLERTON

Protein metabolism in the intestinal stagnant loop syndrome E. A. JONES, A. CRAIGIE, A. S. TAVILL, G. FRANGLEN, and V. M. ROSENOER

An analysis of the insulin test after vagotomy using single and multiple criteria G. GILLESPIE, I. E. GILLESPIE, and A. W. KAY

Effect of five salicylate-containing compounds upon loss of ${ }^{51}$ chromium-labelled erythrocytes from the gastrointestinal tract of normal man WARREN L. BEEKEN

Incidence of primary carcinoma of the liver in the west of Scotland between 1949 and 1965 W. G. MANDERSON, R. S. PATRICK, and ELIZABETH E. PETERS

Slowly evolving widespread diffuse alimentary tract carcinoma (linitis plastica) J. PINTO CORREIA, AMÉLIA S. BAPTISTA, and J. FELIX ANTÓNIO

Acute fatty liver of pregnancy R. A. JOSKE, D. J. MCCULLY, and F. L. MASTAGLIA

Comment

Notes and activities

Copies are still available and may be obtained from the PUBLISHING MANAGER, BRITISH MEDICAL ASSOCIATION, TAVISTOCK SQUARE W.C.1, price 18s. 6D. 